NIETO, Agustín (2018). Entre anarquistas y peronistas. Historias obreras a ras del suelo. Buenos Aires: Imago Mundi/Ediciones CEHTI, 352 páginas.

\title{
Agustín Nieto. Entre anarquistas y peronistas. Historias obreras a ras del suelo. Buenos Aires: Imago Mundi/Ediciones CEHTI, 2018, 352 páginas.
}

Guillermina Laitano

Centro de Estudios Históricos Universidad Nacional de Mar del Plata Consejo Nacional de Investigaciones Científicas y Técnicas

(Argentina) guillermina.laitano@yahoo.com

Entre anarquistas y peronistas. Historias obreras a ras del suelo es el octavo número de la "Colección Archivos" del Centro de Estudios Históricos de los Trabajadores y las Izquierdas y, al igual que la colección, se inserta en una producción académica que está renovando la historiografía de la clase obrera argentina. El libro reconstruye el proceso de formación de la clase obrera de la industria del pescado marplatense que tuvo lugar entre las décadas de 1940 y 1960. La publicación condensa la investigación doctoral de Agustín Nieto, premiada con una mención de Honor por la Asociación Argentina de Investigadores de Historia.
El libro se inscribe en una tradición marxista que parte del concepto de clase como el clivaje ordenador de las sociedades capitalistas, y por ello, el más dinámico y efectivo para desentrañar su desenvolvimiento. No obstante, la complejidad conceptual que Nieto despliega a lo largo de Entre anarquistas y peronistas... cristaliza en una interpretación historiográfica que supera dicotomías analíticas del estilo explotados-explotadores, estado-sociedad, economía-política, conflicto-consenso. Asimismo, incorpora un caudal conceptual que le permite ahondar en las relaciones capital-trabajo a partir de otras dimensiones que profundizan su entendimiento: género, sociedad política, microconflictividad, cultura sindical, fuerza social obrera, comunidad, experiencia.

El despliegue de los instrumentos conceptuales se realiza a "ras del suelo"; expresión que no refiere a una escala de análisis, aunque la implica, sino que supone un posicionamiento epistemológico global por parte del autor. A 
ras del suelo no implica un estudio microsocial en oposición a uno macrosocial, ni propone recortar lo local de un todo nacional o regional, sino que apunta a "dar cuenta de las formas situadas y contingentes de inscripción de las praxis interseccionalistas". Como bien ilustra Omar Acha en el prólogo del libro, a ras del suelo significa, siguiendo la expresión de Clifford Geertz, estudiar "en aldeas" (y no "aldeas"), donde "en" condensa problemas historiográficos de amplio alcance y "aldeas" sólo el referente empírico. Entonces la clase, concepto cimentador de la investigación, lejos de ser la nominación que designa un grupo social, es entendida como expresión de relaciones sociales que se configuran y reconfiguran en el hacerse y deshacerse de la experiencia cotidiana de lxs sujetxs: lxs obrerxs del pescado marplatense expresan subjetividades que moldean y son moldeadas en la fábrica, pero también en las calles, en los hogares, en los sindicatos, en las agencias estatales.

Cuantiosas y diversas son las fuentes que sustentan la investigación. Como estrategia metodológica para su abordaje, el autor despliega la triangulación no solo a nivel de las técnicas, sino también a nivel analítico: a saber, a lo cuantitativo se le repone su significación y a lo cualitativo se lo problematiza estadísticamente. Destaca el análisis de sentencias judiciales, del carnet sindical, de la balanza -elemento central de la relación capital/trabajo en una producción a destajo-, de las asambleas, de prácticas como el hurto -tanto obrerx como patronal-, de trayectorias laborales -individuales y grupales-, de fotografías, amén del análisis más clásico de documentos estatales, empresariales, sindicales, partidarios y de la prensa.
El libro se organiza en cinco capítulos cuyo ordenamiento es cronológico, pero no ceñido únicamente a los tiempos político-institucionales, sino incorporando otros tempos sociales para su organización. Además, las dimensiones analíticas se problematizan transversalmente en todos los capítulos, lo cual habilita al autor a desplegarlas en los diferentes contextos históricos que involucra la obra.

El primer capítulo se titula "Hito en la formación de una comunidad y una identidad obrera". Su objetivo es reconstruir el proceso de lucha que llevan a cabo lxs obrerxs del pescado a principios de los años cuarenta, proceso gestante del Sindicato Obrero de la Industria del Pescado (SOIP). Las características estructurales de la industria pesquera, los rasgos de la fuerza de trabajo y las particularidades del proceso laboral se introducen encadenadamente como insumos para reconstruir el desenvolvimiento específico que asumió la huelga de conformación del SOIP. Por su parte, el análisis del movimiento huelguístico se realiza no solo desde los puntos de vista de las experiencias de lxs obrerxs (y lo señalo en plural porque precisamente el autor da cuenta de la comunidad de los trabajadorxs, pero también de sus disputas internas en el mismo proceso de lucha), sino también desde el punto de vista de los industriales. Finalmente, se inscribe el surgimiento del sindicato del pescado en el marco del desarrollo del anarquismo en Mar del Plata. En el tratamiento de esta dimensión, el autor reconstruye el clima de ideas, pero también las prácticas que caracterizaban al anarquismo marplatense en los cuarenta, y ofrece indicios para repensar la tesis de la extinción del anarquismo a comienzos de la década del treinta. Cabe destacar en este último sentido, la apuesta de Nieto por una historia del movimiento obrero que no se erija solo en 
función de los momentos de auge de las distintas corrientes políticas que lo conducen, sino incorporando también la heterogeneidad de sujetos y corrientes convivientes -en el marco de la "hegemonía" de un grupo particular-.

En el capítulo 2 "Obrerxs anarquistas en la aldea peronista", Nieto se introduce a analizar otras dimensiones que hacen al proceso formativo de la clase obrera del pescado marplatense. Dimensiones que, a diferencia de las huelgas generales -más esporádicas-, cobran riqueza analítica en la cotidianeidad de la vida obrera: la microconflictividad en las fábricas, la formación de una cultura sindical, el clivaje de género en el mundo ictícola, el trabajo infantil y la prensa. Si bien el autor aquí trata de concentrar la atención en cada una de estas dimensiones, lo cierto es que las mismas afloran en muchos otros momentos del libro, dado el análisis relacional que prima en el trabajo. Resaltamos aquí dos de las dimensiones abordadas en este capítulo.

Por un lado, la microconflictividad en los lugares de trabajo. En este apartado el autor analiza las pequeñas disputas fabriles como continuación de las grandes batallas -las huelgas-. De esta forma, Nieto estudia cómo cada vez que lxs obrerxs del pescado firmaban un nuevo pliego con la patronal en el marco de una huelga, luego comenzaba la lucha en las fábricas para que cada patrón cumpla con lo acordado.

Por otro lado, el autor avanza en el análisis del clivaje de género, insoslayable en una industria donde la gran mayoría de lxs trabajadorxs eran mujeres. Su abordaje se inserta en una línea de estudios que ha comenzado a discutir el lugar y las agencias asignadas a las mujeres obreras y sindicalistas en la historiografía hegemónica. Para ello, Nieto reconstruye las experiencias de participación sindical de las obreras -o la ausencia de ella, junto a sus motivos-, la concepción que de la mujer portaba la dirigencia del sindicato en particular y el anarquismo como corriente política en general, las concepciones de las propias mujeres obreras sobre su doble condición de subalternas, y la participación de las mujeres en la vida cotidiana del sindicato.

En el tercer capítulo, "Sindicalismo peronista y conflictividad obrera", emerge una dimensión que ya aparecía operando en los análisis de los capítulos previos, pero que ahora se dedica a profundizar: cómo impactó el peronismo en la conflictividad obrera del mundo del pescado, particularmente en el periodo 1950-1955. En su análisis, Nieto discute con las interpretaciones que, en base a fuentes estadísticas gubernamentales y capitalinas, sostienen que la conflictividad obrera en el segundo quinquenio del gobierno peronista menguó. Por el contrario, el autor da cuenta en el plano local de una dinámica conflictual de mayor complejidad. En el periodo 1950-1955, de hegemonía del SOIPA peronista, se desarrollaron dos huelgas generales, a la par que persistieron los microconflictos registrados para el periodo anterior. La diferencia reside en que para tornarlos observables se requiere acudir a otras fuentes, en particular a las sentencias del Tribunal de Trabajo local. En el análisis de este corpus novedoso, Nieto reconstruye la dinámica conflictual cotidiana entre obrerxs y patrones, la existencia de formas de resistencia obrera subterráneas como el ausentismo y el sabotaje, y un análisis de la propia agencia estatal judicial como dispositivo de individuación de los colectivos subalternos.

"Sindicalismo anarquista en tiempos de proscripción”, cuarto capítulo, analiza el reconfigurarse de la clase obrera del pescado marplatense luego del golpe de 1955 y hasta 1966. 
Desde el punto de vista obrero, el golpe dio lugar a la reorganización del sindicato, que en este periodo transitó primero una hegemonía anarquista y luego una peronista, $\mathrm{y}$ a una activación gremial de lucha dada la ofensiva del empresariado por el nuevo contexto. En este sentido, se abordan relacionalmente tanto el conflicto obrero en relación al empresariado como "procesos capilares de organización" de la propia organización sindical, procesos caracterizados por tensiones intra-obreras.

En lo que refiere al proceso de organización capilar del SOIP, el autor introduce el concepto de fuerza social obrera para analizar las disputas entre la fracción peronista y la fracción anarquista por la conducción del gremio. La propuesta conceptual de Nieto, en diálogo con la tradición de CICSO, expresa la necesidad analítica de abandonar miradas que reproduzcan la instalada dicotomía dirección/bases y piense, en cambio, a los grupos obreros enfrentados como fuerzas sociales, donde cada una se compone de bases y dirigencias. Se trata de fuerzas dispares claro está, pues una, la que se asocia al polo "dirigencia" es una fuerza social institucionalizada (conduce el gremio), mientras que la otra no. Construyendo este instrumento conceptual, el autor da cuenta de ese reconvertirse constante de la clase obrera del pescado, no solo en función de las relaciones que entabla con el capital, sino en función de los procesos internos.

"Fileterxs: los orígenes de una identidad perdurable", capítulo que cierra la obra, se detiene en el desarrollo de un sector de lxs obrerxs del pescado, lxs fileterxs, que comenzó a expandirse hacia la década del sesenta producto de condiciones emergentes de la estructura productiva: la incorporación del fileteado de merluza. En el capítulo Nieto presenta "Algunas 'historias mínimas' sobre avatares comunes en la cotidianeidad fabril [las que] pueden hacernos entender cómo este proceso de mutación 'estructural' fue significado por la comunidad laboral" (p. 215). Da cuenta de los cambios en el mercado de fuerza de trabajo y de las condiciones laborales de lxs fileterxs (a partir de una minuciosa reconstrucción y un sugerente análisis de las trayectorias laborales); de sus repertorios de lucha (abiertos y ocultos); del aprendizaje obrero de las posiciones estratégicas; y de los repertorios de lucha de los empresarios contra este sector particular (el hurto patronal, la balanza descalibrada). También vuelve sobre el análisis de las demandas obreras en los tribunales de trabajo, esta vez deteniéndose en el grupo de lxs fileterxs. Asimismo, analiza el proceso de organización gremial del sector, caracterizado por una fuerte confrontación entre los dos sindicatos que disputaban la conducción de lxs fileterxs (el SOIP anarquista y el STIA de alianza peronista-comunista). En síntesis, este capítulo da cuenta de un conjunto de experiencias en diversos territorios sociales que conformaron a lxs fileterxs en tanto clase, experiencias que continuaron en el movimiento huelguístico de 1965 (final del periodo abordado en el libro). Este movimiento tramitó las últimas disputas entre anarquistas y peronistas por la conducción del gremio del filet y cristalizó el ocaso de la vieja guardia anarquista.

El libro de Agustín Nieto propone y pone en acto una concepción de la historiografía. ¿Qué es hacer historia para este autor? La fotografía de la portada del libro presenta a siete envasadoras con sus delantales blancos, tomadas de los brazos, en la puerta de una fábrica. Son envasadoras de pescado porque esa es la subjetividad que opera de puerta de entrada al investigador, pero una vez traspasado este umbral, 
las identidades de las envasadoras se multiplican: son mujeres frente al orden patriarcal, son obrerxs frente al capitalismo, son base frente a su gremio y dirigentes de una fracción interna, son comunidad de sus compañerxs, pero a veces individualidades, son ciudadanxs frente a múltiples estados, son políticxs en el espacio público. En síntesis, son expresión de una ma1la cuyos hilos son de diversa procedencia, pero que al encontrarse en el mismo tejido mutuamente se afectan, son nudos de relaciones sociales que cabe desatar a quien los historiza.

$$
\propto \ddot{e} \propto
$$

Recibido: 06-03-2019

Aceptado: 06-04-2019

Publicado: 04-06-2019 